\title{
Polymer-Polymer and Copolymer-Copolymer Miscibility in Blends: A Morphological Study
}

\author{
Salah E. M. El-Begawy and M. B. Huglin* \\ Department of Chemistry and Applied Chemistry, \\ University of Salford, Salford M5 4WT, England
}

(Received May 25, 1992)

\begin{abstract}
Curves of instantaneous copolymer composition vs. fractional conversion have been calculated for the copolymerization of $N$-vinyl-2-pyrrolidone (VP) with $n$-butyl acrylate (BA). Low conversion samples of poly(VP-co-BA) possessing minimal heterogeneity in composition, were blended in appropriate proportions so as to simulate the cumulative copolymer compositions produced at various levels of conversion in an actual copolymerization. The phase behavior of these blends has been examined by electron microscopy. The results show that the miscibility between the copolymers within each blend is limited and is a consequence of the compositional heterogeneity predicted from the calculated curves. A morphological study for a series of blends of the homopolymers PVP and PBA was also effected and is discussed.
\end{abstract}

KEY WORDS Scanning Electron Microscopy / Poly $(N$-vinyl-2-pyrrolidoneco-n-butyl acrylate) / Copolymerization / Compositional Heterogeneity / Blends / Polymer Miscibility /

Morphological studies of multiphase amorphous polymers by electron microscopy and often hindered by lack of contrast between the phases. Preferential-solvent etching techniques are usually employed to remove one phase selectively, and subsequently examine the topography of the blend. The authors are at present engaged in the study of polymer miscibility in blends during copolymerization for systems in which blending of polymers occurs simultaneously with their chemical formation, viz., the copolymerization of two monomers $M_{1}$ and $M_{2}$ to various levels of conversion.

In previous publications ${ }^{1,2}$ curves of instantaneous copolymer composition $v s$. fractional conversion $C$, were calculated for different initial feed mixtures containing $N$-vinyl-2-pyrrolidone (VP) and $n$-butyl acrylate (BA) as monomers $\mathbf{M}_{1}$ and $\mathbf{M}_{2}$, respec-

\footnotetext{
* To whom correspondence should be addressed.
}

tively. The values of the mole fraction $f_{1}$ of VP in the feed were $0.821,{ }^{1} 0.956,{ }^{1}$ and $0.772^{2}$ corresponding to $80,95,75 \mathrm{wt} \% \mathrm{VP}$ in the feed, respectively. The values used for reactivity ratios $r_{1}$ and $r_{2}$ were 0.02 and 0.8 , respectively. ${ }^{1,3,4}$ The compatibility within the blends of these systems assessed by light transmission, ${ }^{1}$ glass transition behavior, ${ }^{1}$ solution viscosity measurements, ${ }^{2}$ and solubility parameters, ${ }^{2}$ was in reasonable accord with the compositional heterogeneity predicted from the calculated curves. The objective of the research presented herein is to explore the detailed morphology by electron microscopy and to gain a deeper insight into the phase behavior of the two systems comprising 80 and $95 \mathrm{wt} \% \mathrm{VP}$ in the feed. These compositions are far from the azeotropic composition $\left(f_{1}=0.151\right)$, and hence, are selected here in order to provide reasonably wide ranges in the 
copolymer compositional heterogeneity arising from the disparity in the reactivity ratios of the monomers.

In order to assist assessment of the micrographs of copolymer blends, a morphological study for blends of the homopolymers PVP and PBA is also presented. In these studies, toluene is used as an etching agent, since it is a good solvent for the PBA phase and is a swelling agent for the copolymer blends.

\section{EXPERIMENTAL PROCEDURES}

\section{Materials and Preparation of Blends}

The source, purification of monomers, and mode of preparing low conversion copolymers and the blends have been presented previously. ${ }^{1,5}$ Here, only the main features of the low conversion copolymers (L1-L13), are listed in Table I. The homopolymers PVP (H1) and PBA (H2), and their blends (HB1-HB3) were made up from solution mixtures containing $8 \%$ $(w t / v)$ of each homopolymer in chloroform, with compositions indicated in Table II. For blends of copolymers, calculated curves of instantaneous copolymer composition (ex-

Table I. Characteristics of low conversion copolymers and homopolymers

\begin{tabular}{|c|c|c|c|c|}
\hline \multirow[t]{2}{*}{ Sample } & \multirow[t]{2}{*}{$f_{1}$} & $\begin{array}{l}\text { Reaction } \\
\text { time }\end{array}$ & $\begin{array}{l}\text { Fractional } \\
\text { conversion }\end{array}$ & \multirow{2}{*}{$\begin{array}{c}F_{2} \\
(\mathrm{BA})\end{array}$} \\
\hline & & $\min$ & $C$ & \\
\hline $\mathrm{Ll}$ & 0.840 & 10 & 0.06 & 0.512 \\
\hline $\mathrm{L} 2$ & 0.867 & 15 & 0.07 & 0.482 \\
\hline L3 & 0.938 & 20 & 0.06 & 0.448 \\
\hline $\mathrm{L} 4$ & 0.965 & 25 & 0.04 & 0.407 \\
\hline L5 & 0.978 & 35 & 0.06 & 0.351 \\
\hline L6 & 0.986 & 40 & 0.05 & 0.310 \\
\hline L7 & 0.989 & 45 & 0.02 & 0.257 \\
\hline L8 & 0.993 & 60 & 0.02 & 0.216 \\
\hline L9 & 0.995 & 70 & 0.01 & 0.136 \\
\hline L10 & 0.997 & 90 & 0.01 & 0.111 \\
\hline L11 & 0.999 & 100 & 0.01 & 0.031 \\
\hline $\mathrm{L} 12$ & $1(\mathrm{PVP})^{\mathrm{a}}$ & - & - & 0 \\
\hline $\mathrm{L} 13$ & 0 (PBA) & 180 & 0.26 & 1 \\
\hline
\end{tabular}

a Polysciences, Inc., nominal molar mass $4 \times 10^{3} \mathrm{~g}$ $\mathrm{mol}^{-1}$ pressed as mole fraction $F_{2}$ of BA) at different conversions $C$, were produced (see Figure 1) for the two systems, viz., copolymerizations 80C and 95C, by means of a computer program developed by Yip. ${ }^{6}$ For the former the feed mixture contains $80 \mathrm{wt} \% \mathrm{VP}$ and for the latter, $95 \mathrm{wt} \% \mathrm{VP}$ (corresponding to $f_{1}=0.821$ and 0.956 , respectively). To simulate the copolym-

Table II. Compositions of the homopolymer blends (HB1-HB3) and the copolymer blends $(80 \mathrm{~B} 1-80 \mathrm{~B} 5)$ and $(95 \mathrm{~B} 1-95 \mathrm{~B} 3)$

\begin{tabular}{|c|c|c|c|}
\hline \multirow{2}{*}{$\begin{array}{l}\text { Blend/ } \\
\text { sample }\end{array}$} & \multirow{2}{*}{$\begin{array}{c}\text { Number } \\
\text { of } \\
\text { components }\end{array}$} & \multirow{2}{*}{$\begin{array}{c}\text { Nature } \\
\text { of } \\
\text { components }\end{array}$} & $\begin{array}{l}\text { Corresponding } \\
\text { simulated } \\
\text { conversion }\end{array}$ \\
\hline & & & $C$ \\
\hline $\mathrm{H} 1$ & 1 & $\begin{array}{c}\text { PVP } \\
\text { (sample L12) }\end{array}$ & - \\
\hline $\mathrm{H} 2$ & 1 & $\begin{array}{c}\text { PBA } \\
\text { (sample L13) }\end{array}$ & - \\
\hline HB1 & 2 & $\begin{array}{c}\text { PVP/PBA } \\
(25 / 75 w t \%)\end{array}$ & - \\
\hline HB2 & 2 & $\begin{array}{c}\text { PVP/PBA } \\
\left(50 / 50 w \mathrm{wt}^{\circ} \%\right)\end{array}$ & - \\
\hline HB3 & 2 & $\begin{array}{c}\text { PVP/PBA } \\
(75 / 25 w t \%)\end{array}$ & - \\
\hline $80 \mathrm{~B} 1$ & 2 Copolymers & $\mathrm{L} 1, \mathrm{~L} 2$ & 0.18 \\
\hline $80 \mathrm{~B} 2$ & 4 Copolymers & $\mathrm{L} 1-\mathrm{L} 4$ & 0.32 \\
\hline $80 \mathrm{~B} 3$ & 6 Copolymers & L1-L6 & 0.36 \\
\hline 80B4 & 10 Copolymers & $\mathrm{L} 1-\mathrm{L} 10$ & 0.39 \\
\hline 80B5 & 12 Copolymers & $\mathrm{L} 1-\mathrm{L} 12$ & 0.42 \\
\hline $95 \mathrm{~B} 1$ & 2 Copolymers & L5, L6 & 0.08 \\
\hline $95 \mathrm{~B} 2$ & 4 Copolymers & L5-L8 & 0.10 \\
\hline $95 \mathrm{~B} 3$ & 8 Copolymers & $\mathrm{L} 5-\mathrm{L} 12$ & 0.22 \\
\hline
\end{tabular}

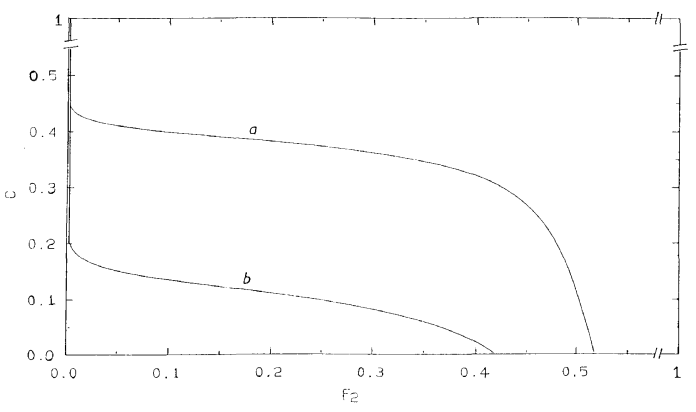

Figure 1. Instantaneous copolymer composition vs fractional conversion $C$, for copolymerzations: (a) $80 \mathrm{wt} \% \mathrm{VP}$ in the feed $\left(f_{1}=0.821\right)$ and (b) $95 \mathrm{wt} \% \mathrm{VP}$ in the feed $\left(f_{1}=0.956\right)$. 
erization $80 \mathrm{C}$, five values of $C$ were selected and for each of these, a blend was prepared from solution mixtures containing $5 \%(\mathrm{wt} / \mathrm{v})$ of total copolymer in chloroform as described previously. ${ }^{1}$ The compositions of these blends (80B1-80B5) are given in Table II. Similarly, to simulate the copolymerization $95 \mathrm{C}$, low conversion copolymers were mixed in proportions to yield the blends $(95 \mathrm{~B} 1-95 \mathrm{~B} 3)$ of compositions given also in Table II.

All blends were cast into films which were allowed to dry slowly in PTFE moulds and then in vacuo at $313 \mathrm{~K}$ for three days to remove the remaining solvent. The thicknesses of the resulting films were $0.5-0.7 \mathrm{~mm}$. Two specimens from each film were glued to the specimen holders by Araldite adhesive. One specimen out of each pair was etched with toluene. The etching time was $21 \mathrm{~h}$ for all the specimens except for the homopolymer blends $\mathrm{HB1}-$ HB3, for which the convenient submerging time in toluene was $3-4 \mathrm{~h}$, as the poly-BA phase was completely dissolved after $6 \mathrm{~h}$. After complete drying in vacuo at $313 \mathrm{~K}$, the surfaces of all the specimens were coated by gold using a conventional sputtering technique. A Cambridge MK 600 Stereoscan Microscope, was used for observation at an acceleration voltage of $20 \mathrm{kV}$. However, for the poly-BA sample $(\mathrm{H} 2)$, the acceleration voltage was reduced to $15 \mathrm{kV}$, in order to avoid the electron beam damage to the surface of the specimen due to the rubbery-like properties of PBA.

\section{RESULTS AND DISCUSSION}

\section{A. Homopolymer Blends}

Homogeneous smooth structures for the films of the homopolymers PVP (H1) and PBA $(\mathrm{H} 2)$, are shown by the scanning electron micrographs in Figures $2 \mathrm{a}$ and $2 \mathrm{~b}$ respectively. Figures $(3 a-3 c)$ show the micrographs of the unetched top film surfaces of the homopolymer blends (HB1-HB3), confirming that variation of morphology with composition occurs and phase separation is clearly observed on a
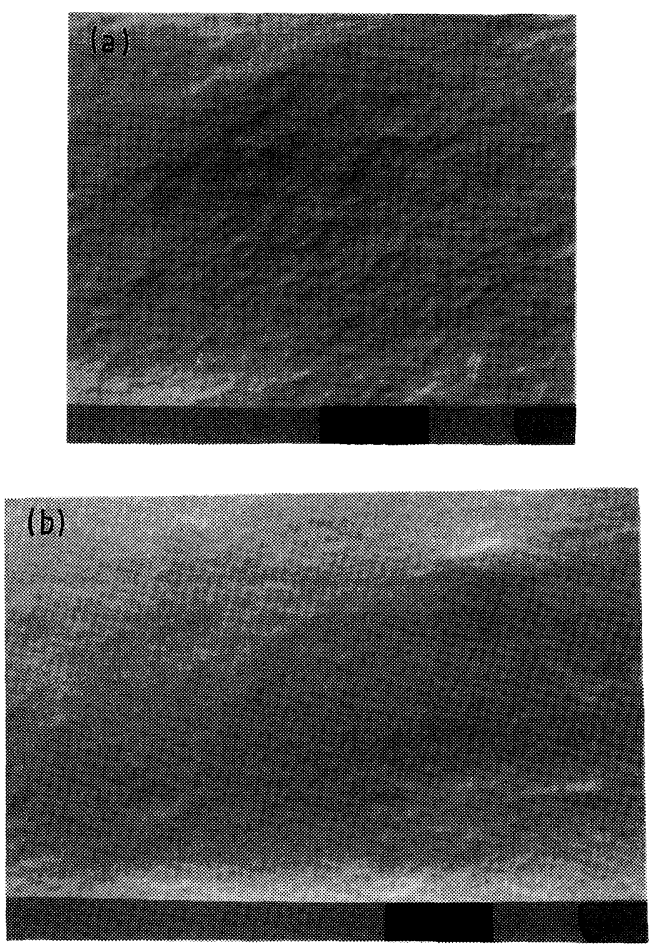

Figure 2. SEM micrographs of the homopolymers: (a) PVP (H1) and (b) PBA (H2).

microscopic scale. In this particular system, it is seen clearly that phases can be distinguished without recourse to etching; the poly-VP phase appears light colored in the form of a slightly uneven surface with some spherical domains in the matrix and poly-BA appears dark and smooth. It will be recalled (Table II) that the PVP content increases in the order (a) to (c) in this figure.

Figures $(4 a-4 c)$ are the corresponding set of the scanning micrographs for the same homopolymer blends after etching. A comparison with the set in Figure 3 illustrates how the morphology of the films is revealed by etching. Figure $4 \mathrm{a}$ shows the emergence of the poly-VP spherical domains accompanying the degradation of the surrounding poly-BA phase. The wide distribution of domain sizes, frequently encountered in blends, can be seen clearly in this micrograph. Under conditions such that the degradable homopolymer is the 

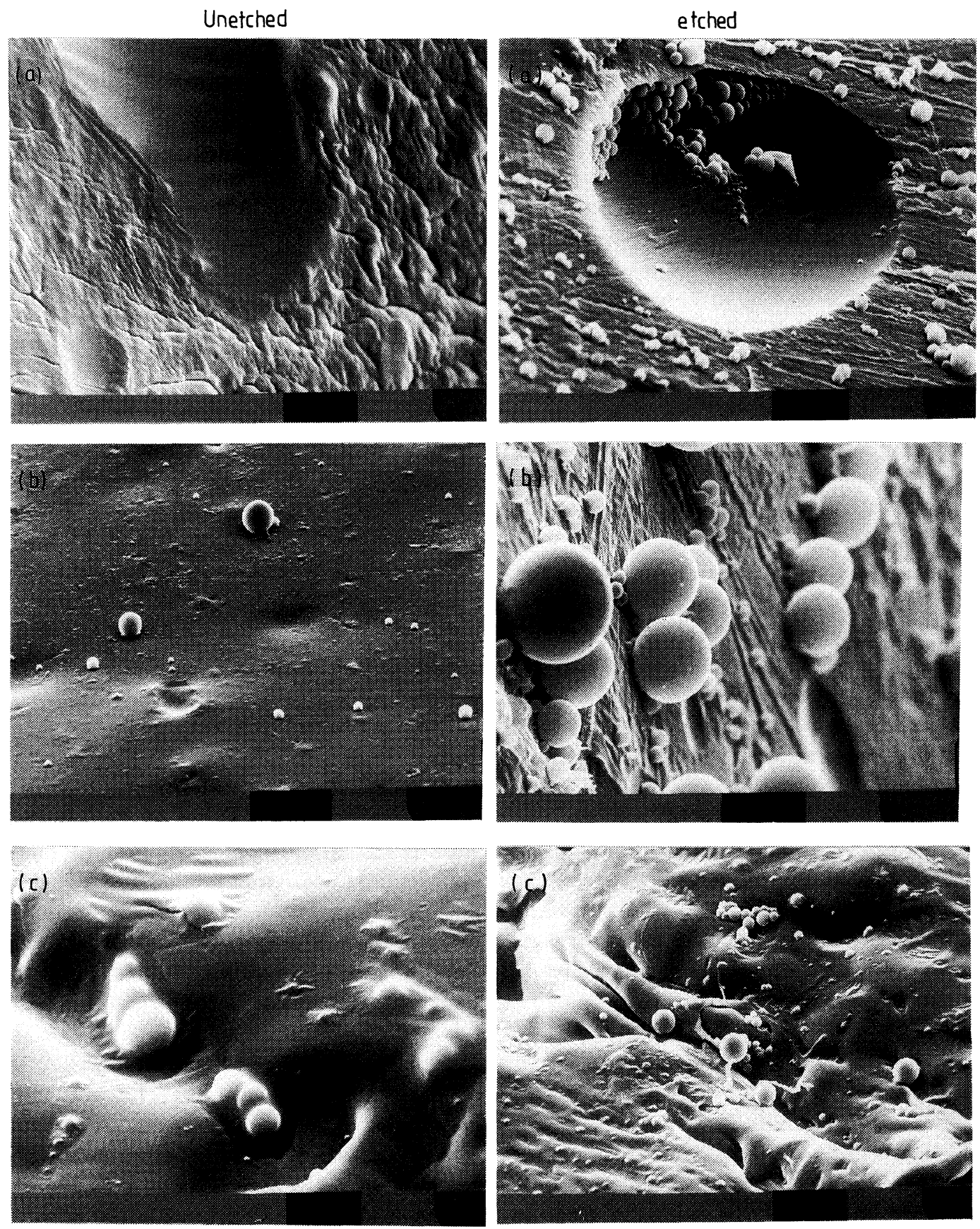

Figure 3. SEM micrographs of the unetched film surfaces of homopolymer blends of PVP/PBA of weight compositions: (a) 25/75 (blend HB1), (b) 50/50 (blend HB2), and

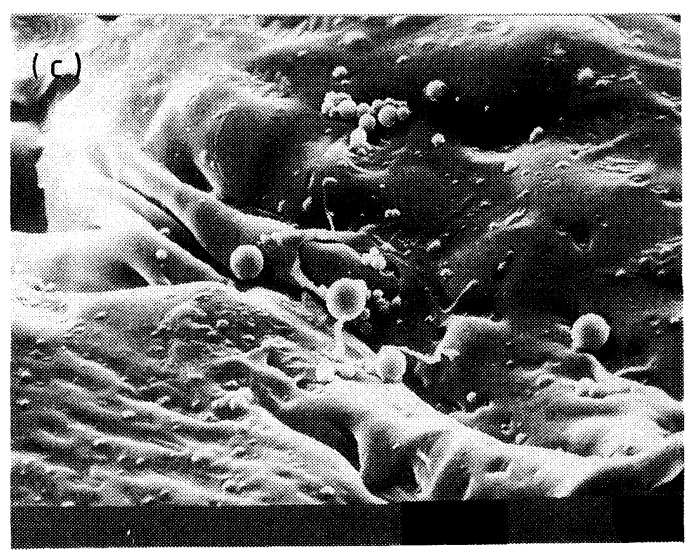

Figure 4. SEM micrographs of etched film surfaces of homopolymer blends (a) blend HB1, (b) blend HB2, and (c) blend HB3. 
matrix, as in this figure, it cannot be expected that all the spherical domains are in their original relative positions. As the matrix is destroyed, the domains will be left essentially unsupported and some may, therefore, be lost when they are completely exposed by the destruction of the surrounding matrix, while some may adhere to the reacting surface as etching proceeds. Nevertheless, the film shows

Unetched
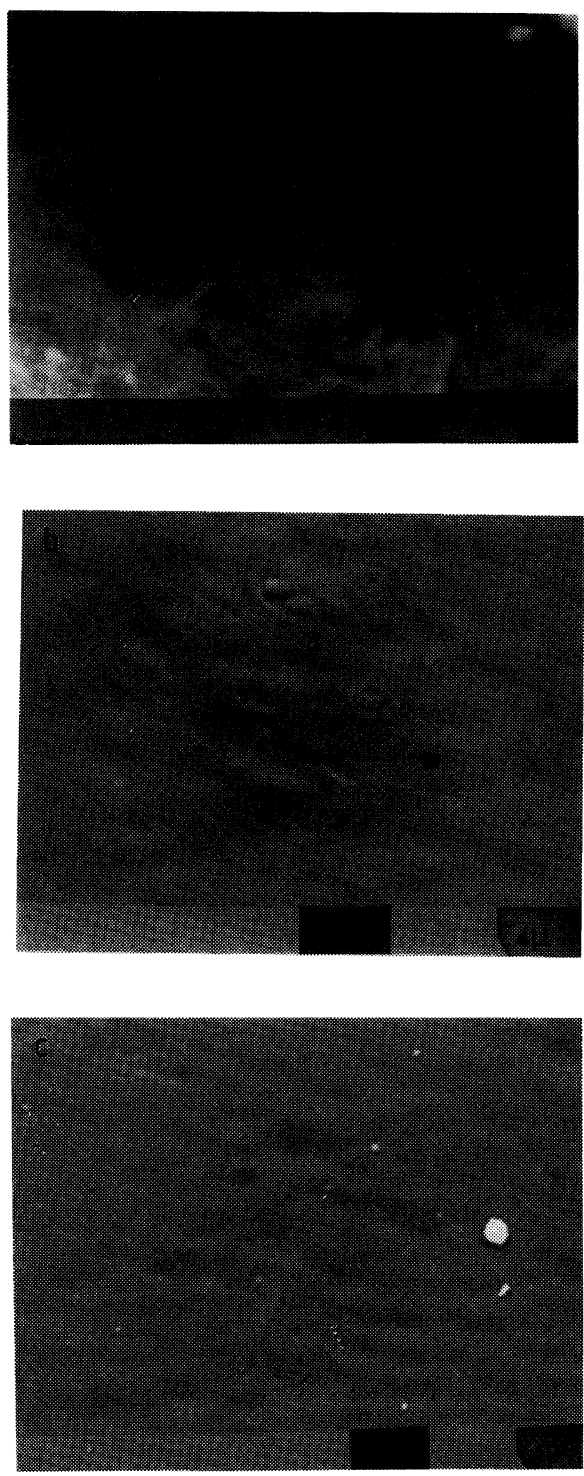

the sizes and shapes of the domains.

Figure 4c (blend HB3) demonstrates the formation of depressions in the surface of the film as surface layers of poly-BA are etched away. The intermediate situation, for a blend containing equal proportions of the constituent homopolymers, is seen in Figure $4 \mathrm{~b}$ which demonstrates the detailed morphology revealed by etching. It may be concluded from the
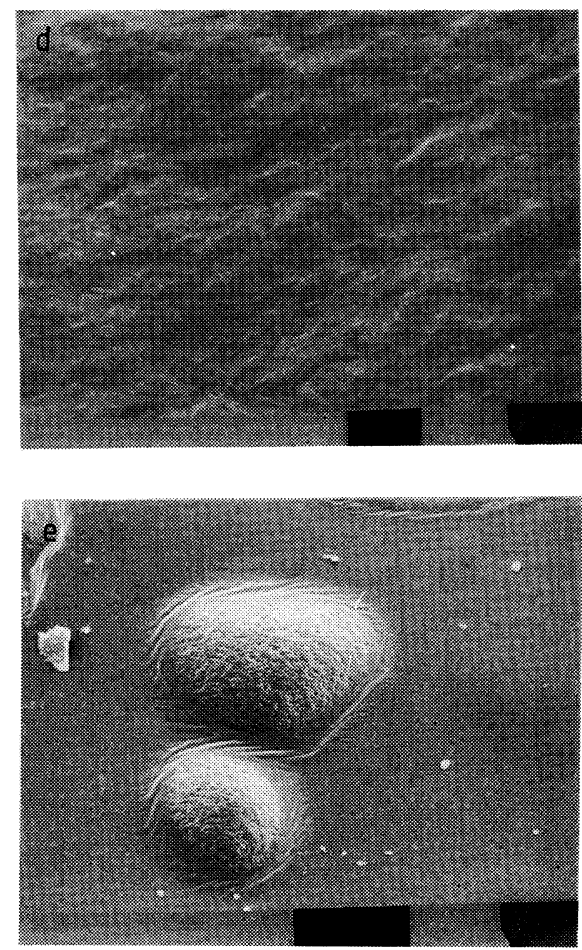

Figure 5. SEM micrographs of unetched films of copolymer blends (a) 80B1, (b) 80B2, (c) 80B3, (d) 80B4, and (e) $80 \mathrm{~B} 5$. 
presence of some immersed poly-VP spherical domains $(3-10 \mu \mathrm{m})$ before and after etching that (i) the poly-VP domains are not artifacts produced during etching and remained unaffected by etching. (ii) a significant phase separation on a microscopic scale occurs.

Examination of the film surfaces for the low conversion samples (L1-L11) has also been carried out. The etching time varied from $18 \mathrm{~h}$

Etched
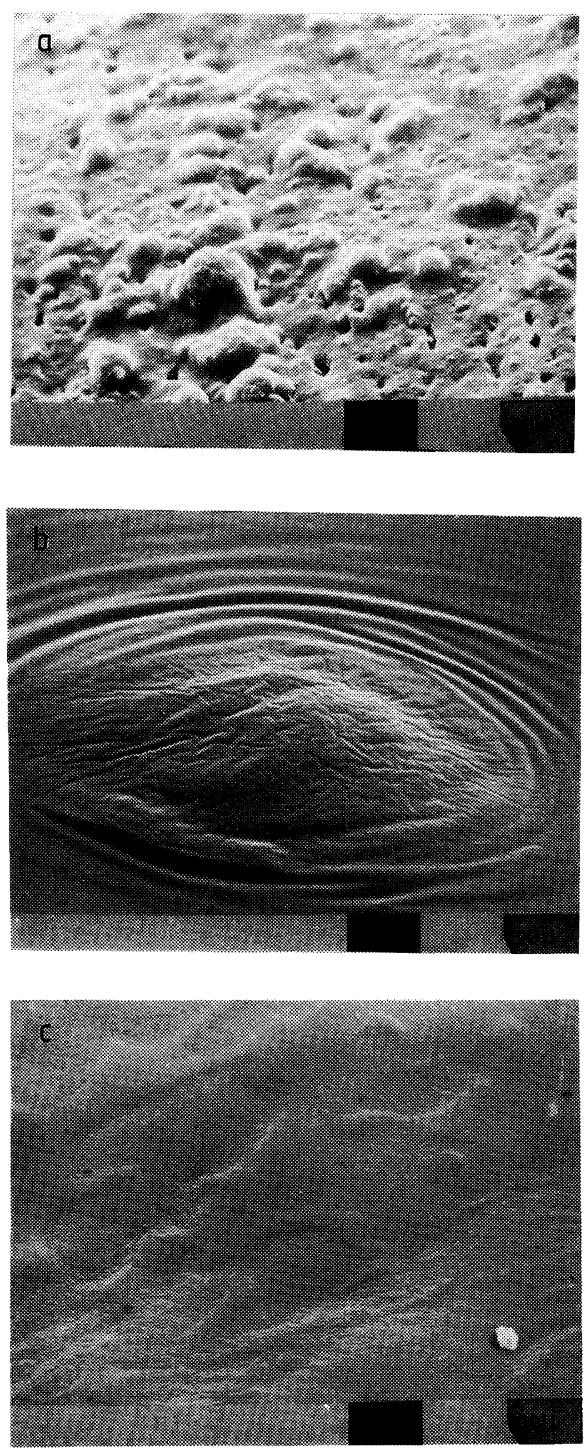

for copolymers with high BA content (samples L1-L5) to $24 \mathrm{~h}$ for those with low BA content (samples L6-L11). The micrographs, which are not reproduced here, revealed the formation of a few pits in the surfaces of the etched films of high BA content. The pits presumably arise from local variations in the structure of the copolymers as they swell in the etching agent.
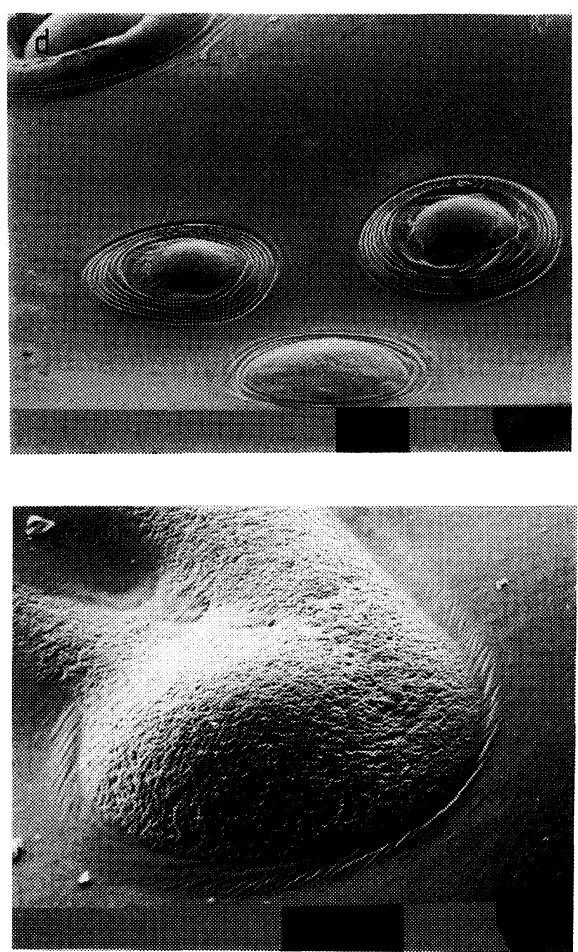

Figure 6. SEM micrographs of etched films of copolymer blends (a) 80B1, (b) 80B1, (b) 80B2, (c) 80B3, (d) 80B4, and (e) $80 \mathrm{~B} 5$. 


\section{B. Copolymer Blends}

With regard to blends $(80 \mathrm{~B} 1-80 \mathrm{~B} 5)$ and (95B1-95B3), it is convenient to consider together the scanning micrographs of each

Unetched
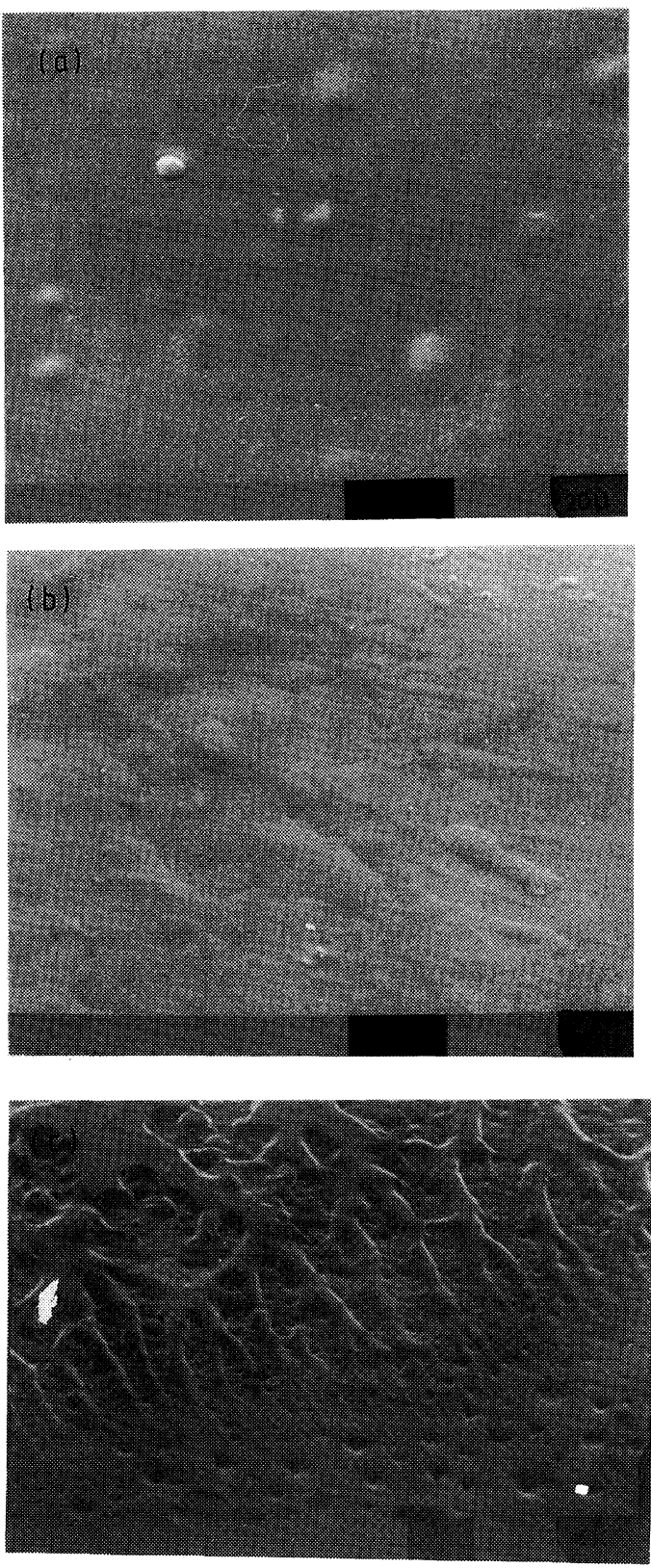

Figure 7. SEM micrographs of unetched films of copolymer blends (a) 95B1, (b) 95B2, and (c) 95B3. system before etching with the corresponding observations after etching. Figure $6 \mathrm{a}$ of blend 80B1 shows a relatively non homogeneous structure as compared with Figure 5a.
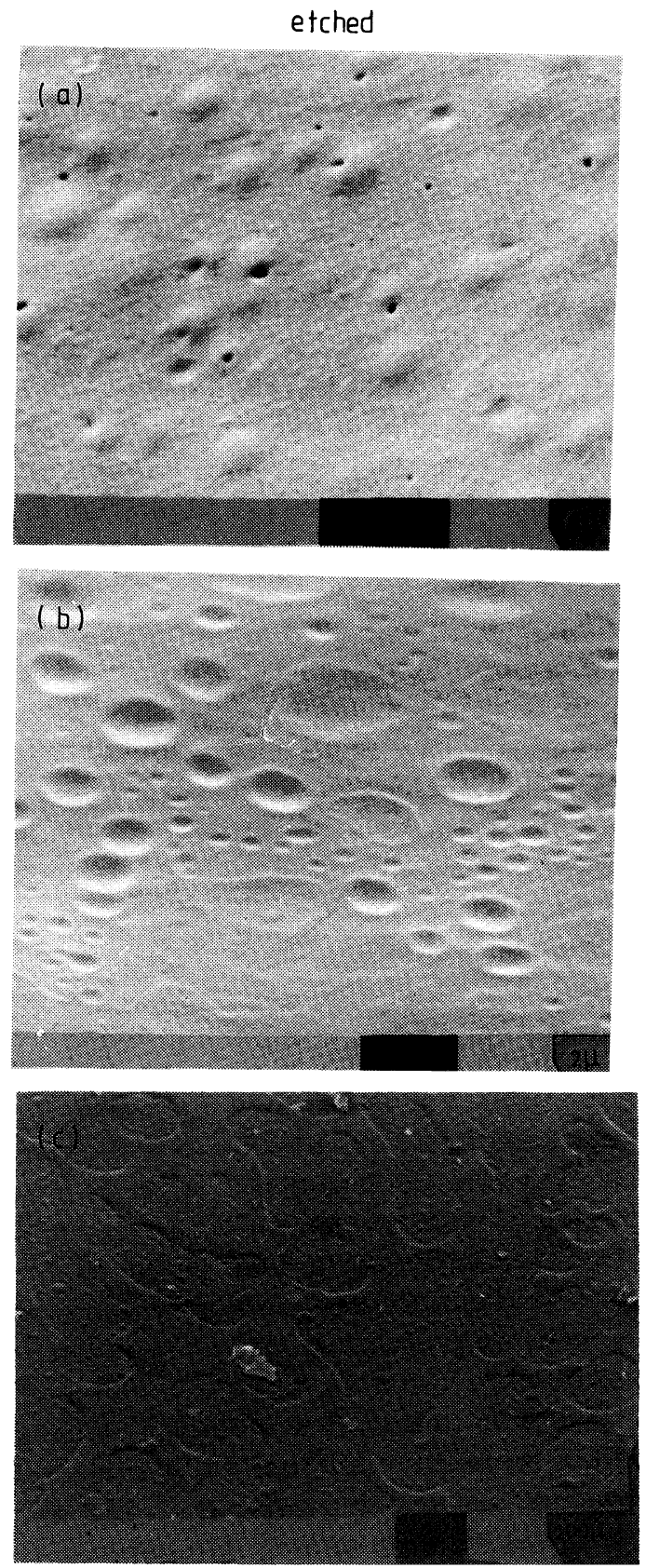

Figure 8. SEM micrographs of etched films of copolymer blends (a) 95B1, (b) 95B2, and (c) 95B3. 
However, the composition of the two copolymers forming the blend, is very similar (see Table II). The etched blend shows also pits formation in the surface which may attributed to uneven etching.

The scanning micrographs reveal changes in blend morphology with the change in composition, as the number of component copolymers mixed increases in the blend. This can be seen clearly in blends 80B3 and 80B4 shown in Figures (5c and $6 \mathrm{c}$ ) and (5d and $6 \mathrm{~d}$ ), respectively. A phase separated structure with two different copolymer domains was observed for the etched film surface of blend 80B3 shown in Figure 6c. The phase separation can also be seen in blend 80B4 in which the formation of separate domains $(10-18 \mu \mathrm{m})$ was observed for the film before etching (see Figure 5d). The etched film shows the formation of cake-like discrete domains $\approx 200-250 \mu \mathrm{m}$ of the same structure separated on a macroscopic scale, thus demonstrating the incompatibility of this blend. Similar domains, but different structure were also observed in the micrographs of blend 80B5, shown in Figures (5e and 6e) demonstrating the formation of distinct boundaries between the constituents of the blend separated on a macroscopic scale.

Scanning electron micrographs of the unetched films of blends (95B1-95B3), are shown in Figures $(7 \mathrm{a}-7 \mathrm{c})$, and the corresponding etched films are shown in Figures $(8 a-8 c)$, respectively. Figure 8 a shows a relatively non homogeneous structure for blend 95B1, made up from two copolymers with different composition. Figure $8 \mathrm{~b}$ shows the micrograph of blend 95B2 containing four mixed copolymers. The figure shows some discrete ellipsoidal domains demonstrating phase separation in this blend.

Figure 7c (unetched film surface of blend 95B3), reveals the existence of two types of structure for the macrodomains. The first appears in the form of long ridges suggesting a poly-VP rich phase in one part of the film, and the second type appears smooth with some pits in the other part of the film, suggesting a poly-BA rich phase. The coexistence of different morphologies in the same film fot this blend, may reflect the non-equilibrium nature of the film. It is widely accepted ${ }^{7-9}$ that, true equilibrium is never achieved for the solvent cast blend films, because the transfer of macromolecules between phases through diffusion is too slow to maintain equilibrium conditions during the process of solvent removal. However, the matter of interest is whether the blend constituents undergo phase separation. Figure $8 \mathrm{c}$ shows the micrograph of this blend (95B3) after etching demonstrating phase separation between the blend constituents on a macroscopic scale.

It is interesting that these observations can be explained in terms of the compositional drift of copolymer with increasing conversion as has been exhibited by these two copolymerizations. In system 80C [Figure 1, curve (a)] the compositional drift is gradual up to $C \approx 0.30$ and thereafter becomes pronounced within the interval $0.32-0.40$. At $C>0.40$, the instantaneous copolymer composition is close to that of poly-VP. Hence, for this system, it is expected that blends simulated at conversions $\leq 0.32$ (see Table II), should exhibit miscibility as evidenced by the observations in blends $80 \mathrm{~B} 1$ and 80B2 (see Figures 6a and 6b). Those blends simulated at selected conversions $>c a .0 .35$ are expected to exhibit phase separation, as also evidenced by the observations in blends 80B4 and 80B5. An intermediate situation is exhibited by blend $80 \mathrm{~B} 3$ at the corresponding simulated conversion.

In system 95C (curve b), the onset of a significant compositional drift becomes evident at a relatively low stage of conversion $(C \approx 0.06)$ and is continuous up to $C \approx 0.16$. From $C \approx 0.2$ onwards the instantaneous copolymer composition is close to that of poly-VP. Comparison of the data in Table II, with the calculated curve of this system indicates that the compositional drift is consonant with the observations in blends $(95 \mathrm{~B} 1-95 \mathrm{~B} 3)$ at the 
corresponding levels of conversion.

It is also clear from the previous ${ }^{1}$ and the present investigations that we are dealing with a case in which miscibility in the copolymer blends can be attained for a certain range of copolymer composition (as seen in blends 80B1 and 95B1) even though the pairs of their corresponding homopolymers are immiscible (as seen in blends HB1, HB2, and HB3). This phenomenon has been explained by the binary interaction model proposed by Kambour et $a l .{ }^{10}$ and extended by Paul et al. ${ }^{11-13}$ and Brinke et al. ${ }^{14}$ According to this model, the intra-molecular interaction between different monomer units in the copolymer is an important factor in inducing the miscibility of the blend. If the mutual repulsion between the dissimilar segments in the copolymer is large enough to overcome the repulsion between these segments and the second component in the mixture, miscibility can be obtained without specific interactions.

On the other hand, Balazs et al. ${ }^{15}$ have shown the effect of sequence distribution and sequence length of the comonomers in determining the relative strengths of inter- and intramolecular interactions. In this respect, the sequence lengths of the comonomer units have been cakculated for the low conversion copolymers (up to an average value of $6 \%$ conversion) employing the procedure adopted by Galvan and Tirrell, ${ }^{16}$ which gives the average length of sequences of $\mathrm{M}_{1}$ units $\left(n_{1}\right)$, and of $M_{2}$ units $\left(n_{2}\right)$. The results of this analysis are given in Table III. Table II and Table III show that blend $80 \mathrm{~B} 1$ made up from low conversion copolymers (L1 and L2) possesses almost equal sequence lengths of VP and BA units, thus favoring miscibility. In the case of blends (80B3-80B5) and (95B2, 95B3), the data show that the components forming these blends have a tendency for large sequence lengths of VP units while those of BA units are very small at all compositions. Hence, the difference in sequence lengths is large enough to induce immiscibility.

In summary, the possibility of using a preferential-solvent etching technique, based on miscibility of PBA and swelling of VP/BA copolymers, to study the morphologies of multicomponent materials has been examined for both blends of homopolymers and copolymers of VP/BA. The sequence of morphologies in the homopolymer blends leads to the conclusion that PVP/PBA is an immiscible system. For the systems compresing copolymer/copolymer blends, the miscibility among the copolymeric constituents of the blends is limited and is shown to be a consequence of the compositional heterogeneity predicted from the calculated curves and the difference in sequence lengths. This conclusion is based on a systematic examination of both homopolymer and copolymer blends covering a wide range of composition combinations.

It is to be mentioned that the precursors of the blends are low conversion copolymers and the procedure adopted for the preparation of blends is only semi-quantitative in nature. The molecular characteristics have not been determined for the sample, but the effect of the sequence lengths of the comonomer units has

Table III. Calculated values of the average sequence lengths of VP units $\left(\bar{n}_{1}\right)$, and of BA units $\left(\bar{n}_{2}\right)$, for the low conversion copolymers ( $\mathrm{L} 1-\mathrm{L} 11)$, up to $6 \%$ conversion

\begin{tabular}{|c|c|c|c|c|c|c|c|c|c|c|c|c|c|c|c|c|c|c|c|c|c|c|}
\hline & \multicolumn{22}{|c|}{$f_{1}=0.840 f_{1}=0.867 f_{1}=0.938 f_{1}=0.965 f_{1}=0.978 f_{1}=0.986 f_{1}=0.989 f_{1}=0.993 f_{1}=0.995 f_{1}=0.997 f_{1}=0.999$} \\
\hline & $\bar{n}_{1}$ & $\bar{n}_{2}$ & $\bar{n}_{1}$ & $\bar{n}_{2}$ & $\bar{n}_{1}$ & $\bar{n}_{2}$ & $\bar{n}_{1}$ & $\bar{n}_{2}$ & $\bar{n}_{1}$ & $\bar{n}_{2}$ & $\bar{n}_{1}$ & $\bar{n}_{2}$ & $\bar{n}_{1}$ & $\bar{n}_{2}$ & $\bar{n}_{1}$ & $\bar{n}_{2}$ & $\bar{n}_{1}$ & $\bar{n}_{2}$ & $\bar{n}_{1}$ & $\bar{n}_{2}$ & $\bar{n}_{1}$ & $\bar{n}_{2}$ \\
\hline & & & & & 1. & & & & & 1 & & & & & & & & & & & & 1 \\
\hline & & 1 & & 1. & 1. & 1. & & & 3 & 1 & 5 & & 1 & 1 & & 1 & & 1 & 41 & 1 & 143 & 1 \\
\hline 0.06 & 1.1 & 1.1 & 1.1 & 1.0 & 1.5 & 1.0 & 2.4 & 1 & 5.0 & 1 & 10 & 1 & 14 & 1 & 34 & 1 & 89 & 1 & 112 & 1 & 407 & 1 \\
\hline
\end{tabular}


been discussed. Here attention is focused on the composition of copolymeric precursors and their blends, rather than on their molecular weights and polydispersity. In any event, polydispersity must be introduced in making up the blends. Viscometric studies ${ }^{2}$ (rather than absolute determinations) have indicated the molecular weights are not exceptionally low; only in the case of oligomers would chain length be a significant factor in the entropy of mixing.

It should also be mentioned that, while electron micrographs may demonstrate the existence of separate phase, allow identification of the major component in a given phase and the determination of domain sizes, the micrographs do not provide information on the composition of the phases. To obtain more information on such systems, electron microscopy must proceed in parallel with measurements which provide information on phase composition such as the glass transition temperature and coefficients of expansion. ${ }^{17}$ The $T_{\mathrm{g}}$ measurements for these systems, reported previously, ${ }^{1}$ were found to be in a reasonable accord with the present findings. However, the single $T_{\mathrm{g}}$ diagnosis for compatibility is subject to certain limitations ${ }^{18}$ and resolution problems regarding $T_{\mathrm{g}}$ may possibly by anticipated in the case of multi-component systems.

\section{Acknowledgements. One of us (S.E.M.E-B)} thanks the Egyptian government for financial support. We wish to acknowledge the help of Mr. G. France (Aeronautical and mechanical Engineering Department) in the SEM work and the helpful discussions provided by Mr. C.
I. Holburn (Manchester Materials Science Centre).

\section{REFERENCES}

1) S. E. M. El-Begawy and M. B. Huglin, Eur. Polym. J., 27, 1023 (1991).

2. S. E. M. El-Begawy and M. B. Huglin, Makromol. Chem., 194, 1105 (1993).

3. M. A. Al-Issa, T. P. Davis, M. B. Huglin, and D. C. F. Yip, Polymer, 26, 1869 (1985).

4. M. B. Huglin and M. M. A.-M. Rehab, Eur. Polym. J., 23, 825 (1987).

5. M. B. Huglin and M. B. Zakaria, Polymer, 26, 1869 (1985).

6. D. C. F. Yip, BSc Dissertation, University of Salford (1984).

7. G. C. Eastmond, M. Jiang, and M. Malinconico, Polymer, 24, 1162 (1983).

8. M. Jiang, X. Huang, and T. Yu, Polymer, 26, 1689 (1985).

9. G. C. Eastmond and D. G. Phillips, Polymer, 20, 1591 (1979).

10. R. P. Kambour, J. T. Bendler, and R. C. Bopp, Macromolecules, 16, 753 (1983).

11. D. R. Paul and J. W. Barlow, Polymer, 25, 487 (1984).

12. E. M. Woo, J. W. Barlow, and D. R. Paul, Polymer, 26, 763 (1985).

13. K. E. Min and D. R. Paul, J. Polym. Sci., Polym. Phys. Ed., 26, 2257 (1988).

14. G. ten Brinke, F. E. Karasz, and W. J. Macknight, Macromolecules, 16, 1827 (1983).

15. A. C. Balazs, F. E. Karasz, W. J. MacKnight, H. Ueda, and I. C. Sanchez, Macromolecules, 18, 2784 (1985).

16. R. Galvan and M. Tirrell, J. Polym. Sci., A, 27, 803 (1986).

17. C. H. Bamford, G. C. Eastmond, and D. Whittle, Polymer, 12, 247 (1971).

18. D. J. Walsh, J. S. Higgins, and A. Maconnachie, (Ed.,) "Polymer Blends and Mixtures," NATO ASI Series E: Applied Sciences No. 89, Martinus Nijhoff Publishers, Dordrecht, Netherlands, 1985, Chapter 2, p 35. 